\title{
Presentació
}

\author{
PAULA QUINTANO MARTÍNEZ ${ }^{1}$ \\ FRANCISCO GIMÉNEZ MATEU²
}

\section{Figuras y arquetipos de género en la Grecia Antigua}

\section{Gender figures and archetypes in Ancient Greece}

El número 39 de la revista Asparkía. Investigació Feminista reúne diversas investigaciones que giran en torno al tema «Figuras y arquetipos de género en la Grecia Antigua», con una miscelánea de trabajos que abordan, bajo una perspectiva interdisciplinar, cuestiones variadas dentro de los estudios de género y de la investigación feminista.

El monográfico pretende mostrar la diferente asignación de papeles, estatus y poder a mujeres y hombres en la Antigua Grecia en función de las variables sexo/género - junto a otras como la estratificación social, el origen étnico o la edad- bajo la perspectiva de que lo femenino y lo masculino, así como los roles de género, son creaciones culturales inmersas en procesos de transformación dependientes de los diversos escenarios espacio-temporales.

Reparar tanto en las inercias y resistencias al cambio, como en el dinamismo de estas construcciones nos ofrece una visión más rica y plural que supera la imagen del mundo griego como un todo uniforme, y pone en cuestión la noción inmutable de Mujer griega - y de Hombre griego-, permitiendo descubrir a sus mujeres -y sus hombres - como un conjunto polifacético, cambiante y plural.

Lejos de pensar de forma monolítica acerca de la condición de las mujeres en la Antigua Grecia y de establecer un recorrido lineal en su valoración, las realidades femeninas variaron en función del contexto geográfico: el ámbito dorio (Esparta y Gortina) y Atenas, junto a sus respectivas áreas de influencia, fueron mundos relacionados y, al mismo tiempo, autónomos. Concibieron el ordenamiento de su comunidad cívica de maneras diferentes y establecieron distintos códigos de género, otorgando a lo femenino y a las mujeres un protagonismo desigual, mayor en el caso de las dorias que en el de las atenienses.

Además, a lo largo de los siglos se registraron cambios en los sistemas de organización social, política y económica que afectaron a toda la sociedad y, por supuesto, también a la posición de mujeres y hombres. Si la valoración social femeni-

1 Mondragon Unibertsitatea

2 Universitat Jaume I 
na de la Grecia arcaica fue decayendo en la sociedad democrática a medida que la democracia griega alcanzaba su esplendor — especialmente en Atenas-, la época helenística supone nuevas oportunidades para las mujeres: su posición mejora y adquieren mayor capacidad de acción. Por ello, y a pesar de encontrarnos frente a una sociedad patriarcal, no pueden eludirse las transformaciones de la situación femenina y de la percepción de las mujeres en público, así como los nuevos modelos de feminidad que se irán conformando según las realidades cambiantes.

De hecho, las cuatro investigaciones que conforman este monográfico se ocupan de contextos cronológicos variados, abarcando desde la época homérica hasta el periodo helenístico. Asimismo, plantean diferentes acercamientos teóricos y prácticos al estudio de lo femenino: desde el análisis de las evidencias visuales de la pintura sobre cerámica; o el estudio crítico de los relatos mitológicos; pasando por el examen combinado de fuentes literarias e históricas; hasta la consideración de reflexiones filosóficas contemporáneas sobre el mito.

Tras la diversidad de planteamientos se pueden descubrir ciertos puntos de unión y aspectos compartidos. Así, todas son conscientes de que la mirada masculina contempla y conforma tanto el plano de la realidad como la esfera de lo simbólico. Además, inciden en la necesidad de revisar y releer críticamente a través de la perspectiva de género las fuentes — textuales, arqueológicas o plásticas-, cuestionando los discursos hegemónicos elaborados, y coinciden en la utilidad de aplicar análisis multifacéticos para una comprensión más completa de la cultura griega antigua.

De tal manera, se explora la figura mítica de Pandora, la primera mujer, considerada más como arquetipo de la feminidad que como una mujer. Desde que Atenea le entregase el arte del tejido, el ámbito textil apareció en estrecha conexión con las mujeres, no solo como actividad y contribución femenina a la economía del ô̂kos, sino como señal de virtud, prestigio y respetabilidad tanto a nivel personal como social. Formaba parte del ideal de mujer, la «novia deseable» convertida a través de la institución matrimonial en «esposa virtuosa» y «madre abnegada», que conformó el modelo tradicional de feminidad. Frente a este, algunas figuras como las Amazonas constituyeron el contramodelo mítico de mujer que, además, reunía junto a lo femenino, lo salvaje y lo bárbaro como construcción de la alteridad frente a la identidad griega y también frente al modelo ideal de varón.

El matrimonio y la maternidad se presentan como ejes centrales de la vida femenina, aunque el hecho de constituir una pareja y fundar una familia no solo fue una necesidad vital para perpetuarse a través de la descendencia, sino también una aspiración para todas aquellas mujeres y hombres que pretendiesen cumplir con los comportamientos normativos de la sociedad griega. No obstante, esas mismas virtudes conyugales y maternales posibilitaron que algunas mujeres, bajo la imagen de rectas cumplidoras del modelo de feminidad tradicional, se asegurasen una presencia y participación pública cada vez más alta aprovechando las nuevas circunstancias del periodo helenístico.

El monográfico se inicia con la aportación de Cora Dukelsky como firma invitada. En su trabajo «Mujeres griegas en las imágenes de la cerámica: novias, esposas, 
tejedoras», analiza algunas de las representaciones de mujeres más frecuentes en la cerámica pintada de la Antigua Grecia. Estas creaciones artísticas, subraya la autora, son construcciones simbólicas que enfatizaban las diferencias de género, no un simple reflejo de la vida cotidiana. Precisamente la abundancia de motivos textiles, escenas de matrimonio y de acicalamiento representa una selección de aspectos de la vida doméstica que evidencian las obligaciones femeninas en función de los valores dominantes de una sociedad patriarcal. Las tareas del tejido y el hilado, específicamente vinculados con la mujer, conformaron el modelo de mujer virtuosa de hermosura serena, comportamiento intachable e incansable laboriosidad. Así, las novias, esposas y tejedoras representadas en la cerámica exponen y sintetizan los atributos del ideal femenino: la mujer bella que contribuye con la procreación al sostenimiento de la polis y la mujer hacendosa que colabora con su producción al mantenimiento del oîkos. Aunque algunas piezas estuvieron vinculadas al ámbito masculino y otras fueron usadas por mujeres, todas fueron creadas por hombres y sirvieron como mecanismo de control de las conductas y expectativas femeninas.

A continuación, presentamos los tres artículos que conforman el núcleo central del número. En primer lugar, Vanessa Pozo García, en «Las domesticadas y el primer arquetipo femenino. Pandora», se adentra en la consideración de lo femenino dentro la mitología griega a través de la obra de Hesíodo y su caracterización de Pandora como génesis de la «funesta raza de las mujeres». Modelada como simulacro de doncella, mediante el artificio, la seducción y el engaño, construida como castigo, su figura sustentó la visión de la mujer como un mal, aunque necesario, que permitirá justificar la domesticación de la naturaleza femenina y el control de su sexualidad y capacidad reproductiva a través del matrimonio. Precisamente la autora analiza la institución matrimonial como instrumento de civilización recurriendo a la narración de Heródoto sobre las Amazonas, antítesis del modelo femenino, que fueron «amansadas» por los escitas al tomarlas como esposas. El matrimonio, junto a la maternidad encauzada dentro de él bajo una estricta monogamia, se convirtió en expresión de la condición identitaria y cívica de la mujer griega y en símbolo civilizador al servicio del sistema patriarcal.

Por su parte, la aportación de Susana Maseda de la Torre reflexiona «Sobre la posibilidad de un mito sororo» centrándose, en concreto, en una escena relacionada con el rapto de Perséfone y la búsqueda emprendida por su madre, Deméter. Afligida y exhausta tras vagar en busca de su hija, se produce el encuentro entre la diosa y Baubo, figura femenina que, con el gesto de levantar su peplo y mostrar sus genitales, consigue hacer reír a Deméter. Su gesto mágico, erótico y apotropai$\mathrm{co}$, sus bromas obscenas reaniman a la diosa abriendo un espacio más allá del dolor, de la pérdida y la muerte, que invita al retorno a la risa, la vida, la fecundidad de las mujeres y la fertilidad de la tierra. Este análisis entrelaza las fuentes originales (los relatos órficos y el Himno homérico a Deméter) con reflexiones contemporáneas sobre el mito, como las de la filósofa Sarah Kofman, y propone interpretar el encuentro como una narración de alianza y sororidad femenina, frente a los más frecuentes relatos de rivalidad entre diosas o entre estas y las mujeres. 
Por último, en «Virtudes domésticas/acciones públicas. Las reinas atálidas y las transformaciones de la feminidad helenística», María Dolores Mirón Pérez nos acerca a la figura de la reina en las monarquías helenísticas, en concreto a las basilissai Apolonis y Estratonice de la dinastía Atálida de Pérgamo. Sus figuras reflejaron y reforzaron los cambios de la sociedad helenística, en especial los procesos de visibilización y reconocimiento público de las mujeres de las élites. Como esposas y madres de reyes, estas reinas fueron convertidas en uno de los pilares de la autorepresentación dinástica como familia unida en el poder. Encarnaban el modelo de feminidad tradicional griega: la sophrosyne (autocontrol, moderación y modestia sexual), la piedad y la devoción religiosa y las virtudes domésticas y familiares, sobre todo relacionadas con la maternidad y como educadoras de sus hijos. Aunque se movieran dentro del paradigma de los valores tradicionales de género, la autora desvela que también desempeñaron un papel público y fueron una figura agente públicamente activa. Sus figuras debieron de constituir un referente para la agencia, la imagen y la memoria de otras mujeres, por todo el mundo griego e incluso el romano.

Seguidamente introducimos los nueve artículos que componen las aportaciones interdisciplinares de la «Miscel-lània». Abriendo la sección encontramos el trabajo de Juan Antonio Cebrián Flores, en «La voz femenina en Thérèse Philosophe», que presenta el estudio de la voz femenina empleada en la novela Thérèse philosophe (especialmente, de los personajes Thérèse y Mme Bois-Laurier), publicada en $1748 \mathrm{y}$ atribuida a Jean-Baptiste de Boye. Porque, como el propio autor recuerda, si bien es cierto que la voz femenina, durante la Ilustración, hace suyas nuevas reivindicaciones, también es cierto que en muchos de los casos son autores masculinos los que dan espacio, en sus obras, a dichas nuevas reivindicaciones. Este es, precisamente, el caso de Thérèse philosophe, que Juan Antonio Cebrián Flores describe como una defensa de la liberación del cuerpo femenino. El autor del texto presenta, así, Thérèse philosophe como el intento de liberación de la mujer, que se encuentra sometida a las reglas fijas e inalterables implantadas por la tradición.

En el segundo trabajo, «Las viajeras francesas en Rusia (1766-1870). Percepciones y miradas sobre el país de los zares», Verónica Gijón Jiménez propone explorar los profundos cambios que se dieron en la Rusia de los siglos XVIII y XIX, a través de una selección de testimonios de mujeres francesas que visitaron el país entre 1766 y 1870. Su mirada quedó plasmada por escrito en forma de libros de viaje, memorias o cartas donde ellas mismas, mayoritariamente, recogieron sus apreciaciones sobre el arte, la cultura y las tradiciones locales e, incluso, su visión crítica acerca de la situación del pueblo ruso. Redescubrir estos nombres propios, testigos directos de algunos acontecimientos históricos fundamentales, permite acercarnos a visiones y entornos a menudo soslayados en la literatura de viaje escrita por hombres y que resultan imprescindibles para comprender la cultura rusa. Aunque no todas dedicaron su vida a luchar activamente por los derechos de las mujeres, en aquella época su determinación viajera transgredía los límites de género.

Tras ello, Carla Torres Llop, en «María Alfonso Coronel y la Casa Medina Sidonia. Dando a luz a la mujer detrás de la leyenda», combina la documentación 
histórica junto con la literatura como fuente histórica para reconstruir y rescatar la figura de María Alfonso Coronel, castellana que vivió en la Andalucía medieval. El teatro de la España del siglo XVIII la transformó en un personaje heroico, junto a su marido, como primeros señores de Sanlúcar y fundadores de la futura Casa de Medina Sidonia. Su figura histórica fue reconstruida como arquetipo femenino recordando las «hazañas» propias de su género, en especial su maternidad, su castidad y su fe cristiana. En tanto se ciñó a su rol de esposa y madre abnegada, fue considerada una figura heroica, encarnación de la mujer virtuosa, de feminidad doméstica y conducta decorosa. No obstante, cayó en el olvido la labor que, como otras mujeres, realizó en la gestión de los negocios y del patrimonio de la casa, asegurando la perpetuación del poder e influencia de uno de los linajes hispánicos más poderosos.

Más adelante, Teresa Samper-Gras, Marcela Jabbaz, Sergio Tomás y Andrea Ferrer, a partir de un estudio efectuado en la Universitat de València, abordan, a través de diferentes miradas y medidas, la problemática de la brecha y desigualdad salarial entre hombres y mujeres (como pueden ser la penalización por maternidad o el plus salarial por paternidad). El análisis se realiza con el objetivo de cuestionar que la maternidad sea el principal hándicap de las profesoras universitarias. La finalidad del estudio consiste en des-naturalizar esta forma de entender la maternidad, para pasar a comprenderla desde un prisma social y cultural (es decir, construido), no tan solo natural. El propio título del artículo resume lo dicho: « $¡$ No son las criaturas, es la Academia! Brechas salariales de género y carrera investigadora en la Universidad».

En quinto lugar, las tensiones y problemas que conllevan el binomio familia y trabajo remunerado, y que se presenta ante las mujeres que trabajan como profesoras universitarias, en cuanto a la compatibilización de los espacios familiar y profesional, es lo que se proponen investigar María del Rocío Guzmán Benavente, Tania Esmeralda Rocha Sánchez, Karla María Reynoso Vargas y Paola Berenice Gurrola Domínguez en ««Caminar con pies de plomo». Estrategias de sostenibilidad en mujeres académicas ante la tensión familia-trabajo». Las autoras, mediante quince entrevistas a profesoras de la universidad pública mexicana, y centradas en sus experiencias personales y sus trayectorias laborales, explican el título de su investigación: «Caminar con pies de plomo», una expresión mexicana que, como ellas mismas describen, denota un caminar lento, un estado de alerta; de preocupación y de precaución.

A continuación, en «Migración de género, passing e inteligibilidad postrecesionaria», Konstantinos Argyriou reflexiona, en un marco posfeminista, postrecesionario e intercultural, acerca de temas relacionados con las identidades y las corporalidades trans, la migración de género, lo no binario o el passing. El trabajo es desarrollado mediante tres diferentes lecturas (representacional, sistémica-prospectiva e intercultural) y es realizado a través de una lectura crítica que aborda distintas propuestas teóricas (estudios transfeministas, queer y CTG) aproximándose, de esta forma, a diferentes modos de percibir lo trans. 
Por su parte, Julia Méndez Hernández, en «Criminología feminista. Una revisión bibliográfica», tal y como su propio título indica, aporta una revisión bibliográfica del poco conocido ámbito de la criminología feminista, es decir, el cuestionamiento de la criminología desde una postura marcadamente feminista, que se centra en el estudio de la criminalidad y de la delincuencia femenina y las cuestiones conexas a ellas. La autora presenta, primeramente, los orígenes patriarcales y androcéntricos de la criminología (y que han marcado su devenir) para después pasar al estudio, en concreto, de la criminología feminista en sí (cuya intención es eliminar la impronta sexista mediante la inclusión de la perspectiva de género). El objetivo último del artículo es ofrecer una recopilación de aquellas publicaciones relacionadas con el campo de estudio de la criminología feminista y que han marcado su devenir.

En octavo lugar, en «Epistemología feminista en la psicología mexicana, una discusión pendiente», Eva Paola Arenas Loera y Mayra Georgina Aguirre Ortiz examinan la ausencia de discusión sobre epistemología feminista; en particular, en la psicología mexicana. Su trabajo muestra que, durante la primera mitad del siglo $\mathrm{XX}$, las psicólogas mexicanas fueron muy pocas en número y, como consecuencia, tuvieron que adherirse a las prácticas patriarcales institucionalizadas. La finalidad del trabajo es demostrar que la actual psicología mexicana necesita preguntarse acerca de las prácticas hegemónicas existentes, desde una posición feminista que incluya el cuestionamiento de conceptos como el de etnia, género, clase social, edad o historicidad.

Antonia Ávalos Torres cierra la sección con su artículo «La Malinche, una Eva indígena: asociaciones misóginas y subversiones simbólicas», donde nos recuerda la necesidad de plantear la historicidad de las construcciones de lo femenino y nos invita a repensar la figura de la Malinche. Asociada con las figuras bíblicas de Lilith y Eva, todas ellas fueron paradigmas de la «mala mujer» frente a la antítesis maternal, sumisa de la Virgen María. La autora incide en la transformación de este personaje histórico, como figura positiva y apreciada, una mujer sabia y poderosa con un rol activo durante la colonización, hasta un personaje simbólico de marcado carácter negativo, metáfora de la deslealtad a la patria y arquetipo de la anti mexicanidad: la anti-heroína, origen y causa de los males acarreados por la conquista. El mito de este personaje ambiguo, al tiempo víctima y culpable, extendió su herencia estigmatizadora al juicio moral hacia las mujeres mexicanas, especialmente las indígenas, sobre quienes ha dejado una profunda huella simbólica.

Finalmente, el número concluye con dos reseñas, incluidas en la sección «Llibres». Por un lado, Feminidades y convivencia política en la antigua Grecia de Ana Iriarte (2020), que realiza un recorrido buscando las conexiones existentes, en la antigua Grecia, entre espacio público y mujeres y espacio privado y hombres. Y, por otro lado, Traducción y violencia simbólica. Reescrituras polifónicas de lo plural cuya edición corre a cargo de Cristina Eugenia Carrasco López (2020) y que está compuesto por un conjunto de trece capítulos en los cuales diferentes autoras y autores se enfocan en el concepto de violencia simbólica, desarrollado por Pierre Bourdieu, y aplicándolo a los llamados Estudios de Traducción. 
No podemos cerrar esta introducción sin mostrar nuestra gratitud a María Juncal Caballero Guiral, por su ayuda en el proceso de edición de la revista; a Maria Medina-Vicent, por su labor en la selección de artículos de la sección «Miscel-lània»; y a la artista Estíbaliz Sádaba Murguía, responsable de las imágenes que cohesionan los contenidos diversos y plurales del número. Igualmente damos las gracias al Instituto Universitario de Estudios Feministas y de Género Purificación Escribano y extendemos nuestro agradecimiento a todas las personas implicadas que han contribuido a hacer realidad este número con sus contribuciones y creaciones, con sus revisiones y aportaciones, o su implicación en labores editoriales y de maquetación. 